\title{
EL PENSAMIENTO ESTÉTICO-PEDAGÓGICO DE JOSEPH BEUYS: ENTRE LA MEMORIA Y LA PERFORMANCE*
}

\author{
The aesthetic-pedagogical thought of Joseph Beuys: between \\ memory and performance
}

\section{Raquel Cercós i Raichs ${ }^{\S}$}

Fecha de recepción: 22/06/2016 • Fecha de aceptación: 01/11/2016

Resumen. La figura del artista alemán Joseph Beuys (1921-1986) destaca no solo por sus creaciones artísticas sino por haber elaborado un complejo y sugerente discurso estético-pedagógico cuyo esbozo ofrecemos aquí. Dos serán los focos de atención que, por su especificidad temporal, presentamos como sigue. El primero arranca de las ruinas de la Segunda Guerra Mundial para abordar cuestiones relativas a la crisis del lenguaje y del sujeto y poner de relieve los esfuerzos del artista por configurar un discurso teórico-práctico sobre la estética de la memoria, un proceso de anamnesis capaz de desarticular el silencio institucionalizado sobre el nazismo. El segundo, rastrea las décadas de los sesenta hasta los ochenta, momento en que Beuys adopta la performance como medio de expresión y exégesis. Un concepto y una práctica a la que se le unirán otros como Formung (formación plástica), plástica social o escultura social que, en última instancia, nos permitirá bosquejar lo que significa la educación en tiempos posmodernos.

Palabras clave: Estética de la memoria; Trauma; Pedagogía; Formación; Bildung; Performance; Posmodernidad.

Abstract. The figure of the German artist Joseph Beuys (1921-1986) stands out not only for their artistic creations but for having created a complex and suggestive aesthetic-pedagogical discourse whose outline we offer here. The focus of attention will be tow and for its temporal specificity the will be

\footnotetext{
$\S$ Departament de Teoria i Història de l'Educació. Facultat d'Educació. Universitat de Barcelona. Paseo del Valle Hebrón, 171. Edificio Llevant. 08035 Barcelona. España. rcercos@ub.edu

" Este artículo forma parte del proyecto Recercaixa «Pensament pedagògic i discursos educatius en la construcció europea cent anys després de la Gran Guerra. Entre el passat i el futur». Un programa impulsado por la Obra Social «la Caixa» con la colaboración de l'ACUP.
}

Cómo citar este artículo: Cercós i Raichs, Raquel. «El pensamiento estético-pedagógico de Joseph Beuys: entre la memoria y la performance», Historia y Memoria de la Educación, 5 (2017): 217-237. 
presented as follows: the first start from the ruins of World War II to address issues relating to the crisis of language and the subject and to highlight the efforts of the artist to set up a theoretical and practical discourse on the aesthetics of memory, a process of anamnesis able to dismantle the institutionalized silence about Nazism. The second traces the sixties to the eighties, when Beuys adopted the performance as a means of expression and exegesis. A concept and practice that will be joined by others as Formung (plastic deformation), social plastic or social sculpture that ultimately allow us to outline what education means in postmodern times.

Key words: Aesthetics of memory; Trauma; Pedagogy; Education; Bildung; Performance; Postmodernity.

Diversos son los autores que, desde varias corrientes historiográficas asociadas al giro cultural y lingüístico, vienen considerando la etapa comprendida entre los años 1914 y 1945 como "La Guerra Civil Europea». ${ }^{1}$ Un concepto hermenéutico que entiende la Gran Guerra, el periodo de entreguerras y la Segunda Guerra Mundial como un fenómeno unitario que a lo largo de treinta años desgarró a todo el continente en una serie encadenada de guerras, revoluciones, deportaciones y genocidios de la que forman parte el fascismo italiano, el nazismo alemán, el comunismo soviético e incluso la Guerra Civil española. De hecho, tal y como apunta Enzo Traverso en su estudio A sangre y fuego: De la guerra civil europea (1914-1945), ${ }^{2}$ a lo largo de estas décadas — aparte de asistir a lo que George Mosse denominó «la brutalización»³ de todas las relaciones sociales- también se problematizaron las categorías jurídicas, políticas, históricas, filosóficas y morales de la herencia ilustrada. Un aspecto que ya fue sistematizado por Hannah Arendt en Los orígenes del totalitarismo, anunciando el derrumbamiento del viejo mundo después de la contienda

\footnotetext{
${ }^{1}$ Ernst Nolte, La guerra civil europea, 1917-1945. Nacionalsocialismo y bolchevismo (México: Fondo de Cultura Económica, 2001); José Luis Comellas, La guerra civil europea (1914-1945) (Madrid: Rialp, 2010); Julián Casanova, Europa contra Europa, 1914-1945 (Barcelona: Crítica, 2011); Paul Preston, «La Guerra Civil europea: 1939-1945», en El siglo XX. Historiografía e historia, ed. M. ${ }^{a}$ Cruz Romeo y Samuel Sanz (Valencia: Universidad de Valencia, 2002), 137-166.

${ }^{2}$ Enzo Traverso, A sangre y fuego: De la guerra civil europea (1914-1945) (Valencia: Publicaciones de la Universidad de Valencia, 2009).

${ }^{3}$ El autor alemán establece en su estudio un lazo directo entre la experiencia de los soldados en las trincheras de la Gran Guerra y la emergencia de los fascismos europeos. George L. Mosse, De la Grande Guerre au totalitarisme. La brutalisation des societés européennes (París: Hachette, 1999).
} 
del catorce, ${ }^{4}$ y Stefan Zweig que observó en el mismo conflicto la crisis de la modernidad y la desaparición del mundo de ayer. ${ }^{5}$

Pero sin duda, fue el 27 de enero de 1945 —fecha en la que los soldados soviéticos del frente aliado llegaron a Auschwitz- el día en que, según Theodor W. Adorno, volver a hacer poesía se podría considerar un acto de barbarie. ${ }^{6} \mathrm{El}$ horror desplegado por los nazis en los Lagers o campos de exterminio ponía de manifiesto el sinsentido de un fenómeno llevado a cabo por unos hombres que eran capaces de tocar a Schubert por la noche, leer a Rilke por la mañana y torturar al mediodía. ${ }^{7}$ Hablamos de la Shoah (palabra judía que hace referencia al sufrimiento del holocausto), un acontecimiento que no podrá ser racionalizado, pues en palabras de George Steiner «La Shoah no es solamente irracional, sino antirrazonable ${ }^{8}$ ya que se encuentra fuera de la palabra y fuera de la razón. Evidentemente, la imposibilidad de pensar Auschwitz representó uno de los aspectos que evidenciaron aún más la fractura entre el sujeto y el mundo, es decir, la imposibilidad de habitar el lenguaje y la consiguiente crisis de sentido.

\section{TRAUMA Y LENGUAJE: LA ESTÉTICA DE LA MEMORIA COMO NEXO PEDAGÓGICO-HERMENÉUTICO}

Bajo las ruinas de una nación derrotada y desolada muchos ciudadanos alemanes, al no encontrar ninguna fuerza que los impulsara hacia el devenir después del trauma del Holocausto, optaron por el silencio, abandonando en lo más profundo del inconsciente los recuerdos del pasado. A vueltas, este estado anímico característico de la Wiederaufbau (re-

\footnotetext{
${ }^{4}$ Hannah Arendt, Los orígenes del totalitarismo (Madrid: Alianza Editorial, 2006), 385-427.

${ }^{5}$ Stefan Zweig, El món d'ahir: memòries d'un europeu (Barcelona: Quaderns Crema, 2001).

${ }^{6}$ Respecto a las relaciones entre poesía y barbarie, Adorno volverá a analizarlas al principio de los años sesenta: «I have no wish to soften the saying that to write poetry after Auschwitz is barbaric; it expresses in negative form the impulse which inspires committed literature. The questions asked by a character in Sartre's play Morts Sans Sépulture [...] Is there any meaning in life when men exist who beat people until the bones break in their bodies?, is also the question whether any art now has a right to exist; whether intellectual regression is not inherent in the concept of committed literature because of the regression of society». Theodor Adorno, "Commitment» en The Essential Frankfurt School Reader, eds. Andrew Arato y Eike Gebherdt (Blackwell: Oxford, 1978), 312.

${ }^{7}$ George Steiner, Lenguaje y silencio. Ensayos sobre la literatura, el lenguaje y lo inhumano (Barcelona: Gedisa, 1994), 25.

${ }^{8}$ George Steiner, Pasión intacta (Madrid: Siruela, 1997), 77.
} 
construcción) propició el afianzamiento de estructuras de represión que negaban el deseo de hacer memoria mediante la productividad exigida y la creación de una nueva realidad sin historia. De ese modo se orientó a la población exclusivamente hacia el futuro y se la obligó a callar sobre lo que había sucedido.

La consolidación de la desmemoria como acto colectivo ya preocupaba a Theodor Adorno; de hecho en su escrito titulado "Qué significa superar el pasado» el filósofo alemán alertaba de las consecuencias morales de la famosa proclama proferida por el Mefistófeles goethiano «Es tan bueno como si no hubiera ocurrido», ${ }^{9}$ pues en ella se desvelaba su principio más profundo: la progresiva pero imparable destrucción del recuerdo. Al igual que él, algunos intelectuales y artistas comprometidos con el renacer de Alemania como la generación Null Punkt (Punto Cero) o el Gruppe 47, iniciaron procesos discursivos en pro de una estética de la memoria. Hablamos de un proyecto regenerador que requería iniciar un proceso de anamnesis - un trabajo personal y colectivo desde la experiencia y mediante la introspección- para superar el duelo de todos aquellos aspectos relacionados con el Holocausto. Se trataba, en definitiva, de hallar elementos estabilizantes o puntos de anclaje para recomponer la traumatizada subjetividad. El camino hacia la construcción de esta nueva Menschenbild (imagen del hombre) indudablemente se dejó sentir en todos los campos artísticos; de hecho, y a lo largo de esta singladura, se produjo una simbiosis teórico-práctica entre el arte y la subjetividad. ${ }^{10}$ Si por un lado la actividad artística permitía la recomposición de esta intimidad resquebrajada a partir de los elementos estabilizadores que ofrecía la pintura abstracta, de otro lado, el arte de vanguardia se rehabilitaba después de la gran purga del nazismo, situándose nuevamente en la escena internacional. ${ }^{11}$

\footnotetext{
${ }^{9}$ Theodor Adorno, Educación para la emancipación (Madrid: Ediciones Morata, 1998), 17.

${ }^{10}$ Las relaciones entre el arte y la construcción de una nueva subjetividad en la Alemania de la posguerra se encuentran originalmente formuladas en el trabajo de Yule F. Heibel, Reconstructing the Subject: Modernist Painting in Western Germany, 1945-1950 (Princeton: University Press, 1995).

${ }^{11}$ Muchas fueron las estrategias empleadas por el Tercer Reich para dinamitar parte de las vanguardias. Una de ellas consistió en la inauguración el año 1937 en la ciudad de Munich de una exposición titulada Entartete Kunst (Arte degenerado) donde se exhibían más de setecientas obras de arte moderno con el único propósito de burlarse de ellas. Subtítulos sarcásticos redactados por Hitler denunciaban la obscenidad, locura, blasfemia y «negritud» (Verniggerund) de este arte en alusión a las derivaciones estilísticas del arte africano. Toby Clark, Arte y propaganda en el siglo XX: la imagen política en la era de la cultura de masas (Madrid: Akal, 2000), 63.
} 
$\mathrm{Y}$ es en este punto donde entra en escena el protagonista de nuestro ensayo. Porque el reconocimiento de Joseph Beuys (1921-1986) se debe tanto a sus aportaciones en el terreno artístico, por haber situado en el contexto alemán los discursos y las prácticas del arte conceptual, el bodyart o la performance — que serán analizados en líneas posteriores-, como por el hecho de impulsar una estética de la memoria; aspecto que estará intrínsecamente relacionado con la esencia de su plástica. Por estética de la memoria nos referimos a un fenómeno eminentemente pedagógico que requería, tanto por parte del artista como del espectador, la capacidad de habitar conscientemente las estructuras represivas y así identificar los fenómenos históricos amenazadores que trataban de imponer el olvido mediante procesos social y psicológicamente organizados.

Para ello, y como paso esencial, el artista alemán realiza un esfuerzo teórico que clama por un arte capaz de sanar la lengua alemana, una lengua enferma de "monolingüismo», es decir, incapaz de conectar con la alteridad. En otras palabras, la lengua se ha vuelto inhumana y demente pues no puede nombrar lo otro y sorprenderse ante el horror. El idioma alemán, en definitiva, ha perdido la fuerza para desmantelar los discursos del poder constituyente y desenmascarar las formas totalitarias.

La locura del lenguaje, el hecho de que una lengua pueda volverse loca por sí misma y convertirse en la locura misma, la locura en la ley, será un aspecto que también desarrollará más tarde Jacques Derrida en su escrito El monolingüismo del otro, la prótesis del origen (1996). Según el filósofo francés, las relaciones entre la barbarie nazi y la lengua están intrínsecamente imbricadas:

Para que los «sujetos» de una lengua se vuelvan «locos», perversos o diabólicos, malvados de un mal radical, la lengua ha tenido que intervenir en ello; ha debido tener su parte de responsabilidad en lo que hizo posible esta locura; un ser no hablante, un ser sin lengua «materna» no puede volverse «loco», perverso, malvado, asesino, criminal o diabólico. ${ }^{12}$

\footnotetext{
12 Jacques Derrrida, El monolingüismo del otro, la prótesis del origen (Buenos Aires: Manantial, 1997), 104.
} 
Existe pues, y el Holocausto da fe de ello, la posibilidad de que el ciudadano hablante se vuelva loco en la locura, y que las mismas palabras pierdan o perviertan su sentido presuntamente común. En efecto, como también manifestara Zigmund Bauman, el lenguaje tecnocientífico y burocrático propio de la modernidad no se comprenderá si se excluye de él algo como el nazismo. ${ }^{13}$ Esta relación entre el lenguaje y la experiencia, problematizada por los autores arriba citados, también formó parte del pensar, el sentir y el escribir de muchos supervivientes de la barbarie que, como Imre Kertész, Elie Wiesel o Paul Celan - entre otros- se vieron obligados a adoptar nuevas formas expresivas debido a la imposibilidad de narrarse con el lenguaje heredado y poder reflejar en sus obras la destrucción y el desgarro de la memoria individual y colectiva. Una postura que manifestaba fehacientemente el desgarro de la cultura europea después de la hecatombe.

Es necesario, por tanto, volver a la fuente de la lengua, una lengua que debemos asociar a la escultura puesto que es la encargada de dar forma a las ideas. Estas fueron las palabras pronunciadas por Joseph Beuys en una conferencia titulada Discurso sobre mi país el año 1985. ${ }^{14}$ Y es que para él la lengua debe ser hablada conscientemente; solo así se forjarán nuevos significados que darán forma al sentimiento y a la voluntad configurando un humus de representaciones sobre el cual puede crecer una forma viva y así posibilitar la curación psíquica. Únicamente en la revolución de los conceptos se hallará la salida a la crisis en la que se encuentra sumido el organismo social. El arte se erige entonces como elemento transformador puesto que es capaz de introducir cuñas en los conceptos existentes, dinamitando los lugares comunes, las imágenes e incluso los paradigmas del lenguaje, facilitando la variación y el cambio.

\footnotetext{
${ }^{13}$ El sociólogo polaco Zigmund Bauman estima que el Holocausto fue la huella indeleble de nuestra animalidad y el producto específico de las sociedades racionalizadas, tecnificadas y burocratizadas. Zigmund Bauman, Modernidad y Holocausto (Madrid: Sequitur, 2006).

${ }^{14}$ El texto se leyó en los Kammerspiele de Múnich dentro del ciclo Reden über das eigene Land: Deutschland (Discurso sobre el propio país: Alemania). La primera publicación tuvo lugar en Reden über das eigene Land: Deutschland (Múnich: Bertelsmann Verlag, 1985). Asimismo existen varias versiones en español: «Discurso sobre el propio país: Alemania», en Joseph Beuys. Ensayos y entrevistas, (Madrid: Síntesis, 2006); «Hablar del propio país: Alemania», en Joseph Beuys. En torno a la muerte de Joseph Beuys. Necrologías, ensayos, discursos (Bonn: Inter-Nations, 1986). En nuestro caso hemos utilizado la versión traducida en la edición de Carmen Bernárdez Sanchís «Discurso sobre mi país», Joseph Beuys (Hondarribia: Nerea, 1999).
} 
Una metamorfosis que también pasa por la necesaria problematización de cuestiones epistemológicas concernientes al arte y su productibilidad.

La fuerza para el cambio que el artista alemán le otorga al arte, nos remite a muchos de los ideales elaborados por el romanticismo alemán. ${ }^{15}$ Ideales que destacan por el deseo de crear una utópica resurrección de la humanidad donde el papel del artista —a modo de chamán o político- jugará un rol fundamental en esta siempre anhelada trasformación social. Sin duda, las relaciones que estableció Beuys con esta corriente de pensamiento - y especialmente con Schiller, Novalis y Goethe- están intrínsecamente relacionadas con este anhelo terapéutico que intentaba dar con la respuesta a las necesidades individuales y colectivas. Una respuesta imposible de hallar sin el conocimiento de los hechos históricos y de las consecuencias éticas que de ellos se infiere.

Porque nuestra existencia, tanto individual como colectiva, no será elaborada a partir del "ahora y el aquí», sino mediante la postura que se adopta frente al pasado y al futuro. Sin duda, la cita de Hannah Arendt cuando sostiene que «el pasado jamás muere, ni siquiera es pasado, se yergue como una fuerza que nos impulsa hacia adelante, siendo contrariamente el futuro, el que nos lleva hacia el pasado», ${ }^{16}$ ejemplifica ese sentir romántico y beuysiano considerado por Paul-Albert Plouffe como "la vivencia de una "temporalidad regresiva" ". ${ }^{17}$ Ambos protagonistas — salvando las diferencias de cada período- se encontraban viviendo en una época en la que no llegaban a reconocerse. No sorprende, entonces, que tanto los románticos del siglo dieciocho como Beuys optaran mayoritariamente por autoexiliarse de un tiempo en el que no se reconocían. La adopción de esta postura implicaba iniciar un proceso de «auto-alienación» donde el artista, volcándose hacia su mundo interior, intentaba hallar la analogía perdida entre la Divinidad, el Hombre y la Naturaleza. Este retorno a los orígenes, esta necesidad de «sentir el pensamiento y

\footnotetext{
${ }^{15}$ La decisión de incluir a Joseph Beuys en la exposición itinerante, The Romantic Spirit in German Art: 1790-1990, celebrada en la Scottish National Gallery of Art (Edinburgo), en la Hayward Gallery (Londres) y en el Alte Museum (Berlín) entre 1994-1995, está explícitamente basada en reconocer la influencia de esta corriente de pensamiento en sus vertientes estéticas, políticas y filosóficas. Keith Hartley (ed.), The Romantic Spirit in German Art: 1790-1990 (Londres: Thames and Hudson, 1994).

${ }^{16}$ Hannah Arendt, Entre el pasado y el futuro: ocho ejercicios sobre la reflexión política (Barcelona: Península, 1996), 16.

${ }^{17}$ Paul-Albert Plouffe, «Joseph Beuys: Avers et revers», Parachute, 21 (1980): 34.
} 
pensar el sentimiento» implicaba elaborar un discurso orientado a dar servicio a las ideas y a las emociones, reclamando a su vez nuevas conceptualizaciones de belleza gracias al amparo de la razón poética en aras de englobar la totalidad. En última instancia lo que se pretendía era llegar a vivir en un siempre utópico estado de unión entre toda la humanidad.

Huelga decir que en las acciones emprendidas por Beuys se percibe el intento por asumir la culpa o la vergüenza de haber formado parte de un pueblo capaz de cometer los mayores crímenes contra la humanidad. Porque recordemos que el artista, nacido en la ciudad Krefeld en 1921, hijo de una familia de origen holandés y de marcada religiosidad católica, fue arrastrado por el Zeitgeist (espíritu de la época). En efecto, como parte integrante de las Juventudes Hitlerianas también se vio abocado a participar en la Segunda Guerra Mundial, primero como radiotelegrafista en la Luftwaffe y después como artillero y piloto de bombardero. En invierno de 1943, durante un ataque a una base rusa en Crimea, su avión fue abatido causando la muerte al piloto y dejando a Beuys gravemente herido. Es así como las secuelas físicas y psíquicas sufridas en este incidente se convertirán más adelante en parte de su experimentación artística. Porque las heridas, aquellas que nunca sanan ni pueden sanar, no dejan de aflorar de forma consciente o inconsciente. De tal modo que la representación y repetición de temáticas y materiales orgánicos o primarios - como la grasa o el fieltro- ${ }^{18}$ son un indicio del esfuerzo por reconciliarse con su pasado y de la voluntad de ofrecer una respuesta a lo que significa crear estéticamente en las postrimerías del fascismo y el genocidio. $^{19}$

Pero es evidente que la herida no sana. Más de veinte años después de la Segunda Guerra Mundial las emergentes formas políticas, jurídicas y democráticas que adopta el Estado determinan un presente donde la cultura de consumo y el dominio de la economía de mercado eliminan de

\footnotetext{
${ }^{18}$ La estrecha relación entre el uso de materiales «primitivos» y la búsqueda de una identidad personal y social por parte del artista estaría vinculada con la necesidad de plantearse aspectos relacionados con la historia social y cultural europea, tal y como se desprende de la siguiente cita: «[T]han beg, borrow or steal from 'primitive' sources to achieve a modern look, Beuys precluded a modern look by making his things as materially raw - radically one might even say prehistorically, unrefined - as possible, thereby saving the primitive from an artistic destiny» en Donald Kuspit, «Beuys: Fat, Felt, and Alchemy», The Critic Is Artist: The Intentionality of Art, UMI Research Press, Ann Arbor (1984): 347. ${ }^{19}$ Lisa Saltzman, Anselm Kiefer and Art after Auschwitz, (Cambridge: Cambridge University Press, 1999), 2.
} 
nuevo los conceptos tradicionales de formación y experiencia del sujeto. De ahí que Beuys llegue a la conclusión de que

la condición humana es Auschwitz, y el principio de Auschwitz se perpetúa en nuestra concepción de la ciencia y de los sistemas políticos, en la delegación de nuestra responsabilidad a grupos de especialistas [...] creo que ahora estamos experimentando Auschwitz en su aspecto contemporáneo. ${ }^{20}$

\section{ENTRE LA BILDUNG Y LA FORMUNG: LA PERFORMANCE COMO ARTE VITAL}

Como la cultura está puesta al servicio de las fuerzas reactivas que la desnaturalizan, el arte - como artefacto político- debe continuar teorizando y evolucionando a fin de poder ofrecer respuestas a las complejidades de un mundo que, a finales de los sesenta, ya abrazaba los aires posmodernos. Por consiguiente, el arte burgués que la modernidad legó, solo al alcance de una minoría y alejado de las necesidades del ser humano, ya no tiene cabida en los tiempos de oscuridad. ${ }^{21}$ Tampoco entraban en el universo del escultor muchos de los aspectos relacionados con las políticas de los movimientos de vanguardia y neovanguardia puesto que, en su opinión, habían fallado en reconectar al arte con la vida. Un fracaso que se hacía evidente al contemplar cómo aquellos antaño transgresores Ready-mades ya formaban parte del ámbito museístico, precisamente aquel símbolo del arte institucionalizado que esperaban derrocar. De ahí los esfuerzos por liberar al arte de la galería, lanzarlo al mundo e iniciar un proceso que llegara a configurar de forma fluida los límites entre las artes y entre el arte y la vida.

Partiendo de estas premisas, se inicia la reflexión sobre el papel del artista y el espectador. Factor que obligó a actualizar las teorías de la estética de la recepción desplazando el énfasis sobre el objeto a favor de la concepción del proyecto. Una postura que, en su vertiente crítica, se vio influida por nuevos métodos de análisis relacionados principalmente con

\footnotetext{
${ }^{20} \mathrm{Hal}$ Foster, et al. Arte desde 1900: modernidad, antimodernidad, Posmodernidad (Madrid: Akal, 2006), 485.

${ }^{21}$ Nos referimos a aquellos tiempos posteriores a la llamada Guerra Civil europea que Hannah Arendt definirá como época oscura, tal y como se traduce de su libro titulado Hombres en tiempos de oscuridad (Barcelona: Gedisa, 1990).
} 
las teorías del lenguaje, el estructuralismo o la semiótica, sin olvidar el influjo del marxismo, los feminismos o el enfoque psicoanalítico a partir de las teorías lacanianas. Referentes teóricos que dieron lugar a un giro copernicano, pues a partir de entonces el público receptor y sus conductas perceptivas, imaginativas y creativas conformaron el foco de estudio y creación artístico.

Despertar al espectador de su letargo y de su pasividad frente a la vida en un intento de movilizar a la ciudadanía se convirtió en el principal objetivo de un arte - mesiánico y revolucionario- que prometía la cura y la salvación. A partir de la proclama «Jeder ist ein Künstler» «Cada cuál es un artista», ${ }^{22}$ Joseph Beuys, siguiendo los latidos del sentir de la década de los sesenta, elabora un discurso sobre la igualdad de los hombres y de su capacidad para producir el cambio. Como «artistas», insistirá el alemán, deberíamos reconocernos como agentes libres y transformadores de entidades, modos de acción y valores.

Only on condition of a radical widening of definitions will it be possible for art and activities related to art [to] provide evidence that art is now the only evolutionary-revolutionary power. Only art is capable of dismantling the repressive effects of a senile social system that continues to totter along the death line: to dismantle in order to build "A SOCIAL ORGANISM AS A WORK OF ART» [...] EVERY HUMAN BEING IS AN ARTIST who - from his state of freedom - the position of freedom that he experiences - at firsthand- learns to determine the other positions of the TOTAL ART WORK OF THE FUTURE SOCIAL ORDER. ${ }^{23}$

\footnotetext{
${ }^{22}$ Para el artista del Renacimiento alemán Alberto Durero (1471-1528), el arte significa que todo ser humano tiene en su propia mano la posibilidad de hacerse a sí mismo lo que quiere ser. Mediante el recto uso de su espíritu, todo hombre puede y debe asimilarse a la verdad en Cristo. Así pues, y según Peter-Klaus Schuster, «no es Beuys el primero en ver un artista en cada hombre, sino Durero, en virtud de sus convicciones humanistas». Pero entre Durero y Beuys no podemos olvidar a los románticos que, como Novalis o posteriormente Nietzsche y más adelante Rudolf Steiner, reformularon ese concepto llegando a ser en los sesenta el leitmotiv de las neovanguardias estéticas en aras de diluir las fronteras entre el arte y la vida. Peter-Klaus Schuster, «El hombre creador de sí mismo. Durero y Beuys o la profesión de fe en la creatividad», Elementos, 26, 4 (1997): 55-59. Joseph Beuys y Clara Bodenmann-Ritter, Joseph Beuys: cada hombre, un artista: conversaciones en Documenta 5-1972 (Madrid: Editorial Visor, 1995).

${ }^{23}$ Joseph Beuys, Koepplin Dieter y Caroline Tisdall, Joseph Beuys: The Secret Block for a Secret Person in Ireland (Basilea: Kunstmuseum, 1977). Se reproduce el uso de mayúsculas tal y como aparecen en el texto.
} 
El discurso, de marcado carácter antropológico y pedagógico, bebía de las fuentes de autores tan dispares, pero tan representativos de la cultura europea como Leonardo da Vinci, Francisco de Loyola, los ya mencionados románticos Goethe, Novalis o Schiller, las sospechas de Nietzsche y la antroposofía de Rudolf Steiner. Lecturas reinterpretadas y adaptadas a los nuevos tiempos que permiten revisar los conceptos, los discursos y las narrativas de la época contemporánea y el desarrollo de la subjetividad moderna y posmoderna. Gracias a Rudolf Steiner ${ }^{24}$ y su concepto de materialismo, Beuys critica una cultura incapaz de liberarse de las ataduras de la fascinación del yo, que ha abusado del uso de la razón y, por consiguiente, ha perdido sus raíces y el sentido de las posibilidades espirituales inherentes a todo ser humano. Porque a su entender, solo el ser humano que se reconoce a sí mismo como ser espiritual en un contexto más elevado es apto para resolver tareas sociales. De ahí su empeño en reclamar una manera mejor de pensar, sentir y querer, pues en ellos residen los auténticos criterios estéticos. En otras palabras, vincular el arte con la vida.

Siempre partiendo del lenguaje, adaptando y creando nuevos conceptos, el artista alemán conformará su discurso político basado también en la triple estructura del organismo social del impulsor de la antroposofía. ${ }^{25}$ Elaborado desde una concepción antropomorfa y organicista, y tomando al hombre como modelo tripartito compuesto por cabeza, sistema rítmico y metabolismo, su correspondencia en el esquema social vendrá dada por la vida intelectual, la vida económica y la vida jurídica regidas a su vez por una nueva interpretación y ampliación de los grandes principios de la Revolución francesa: libertad, sin la cual es impensable la vida intelectual; fraternidad y solidaridad, que será el nuevo principio de la vida económica; igualdad, como principio que preside la vida jurídica ya que el hombre aspira a ser un igual entre iguales. Esta igualdad entre hombres supone una confianza innegable en las facultades creativas de todo individuo que, sin

\footnotetext{
${ }^{24}$ Es evidente que la antroposofía de Rudolf Steiner marcó definitivamente el pensamiento de Joseph Beuys, no en vano, en 1978 entró a formar parte la sociedad Antroposófica. También destacamos cómo los estudios realizados por Steiner sobre Cristología sirvieron al artista alemán a la hora de configurar parte de sus tesis estéticas. Así, a partir del concepto del impulso de Cristo, Beuys dejará de preguntarse por la imagen del Jesús histórico y su desarrollo en la historia del arte para pasar a preguntarse sobre su incidencia en las personas llegando a la conclusión de que «Toda actividad humana está acompañada por ese yo elevado, habitado por Cristo, que vive en los seres humanos, esto es, el impulso de Cristo» en Friedhelm Mennekes, Pensar Cristo (Barcelona: Herder, 1997), 196.

${ }^{25}$ Rudolf Steiner, Le triple aspect de la question sociale (Paris: Librairie Fischbacher, 1921).
} 
duda, deben ser perfeccionadas y reconocidas. Se desprende, por tanto, que la transformación social implica, ante todo, una responsabilidad personal. Porque, según Beuys, todo empieza con uno mismo, porque recordemos que «cada cuál es un artista» y, por ende, todo individuo debería mirarse a sí mismo, formularse a sí mismo como lengua aquello que exige la sensibilidad y el pensamiento para poder desarrollar juntos el «concepto ampliado del arte», un principio también formulado por Nietzsche, ${ }^{26}$ capaz de modificar la forma antigua, muerta o aletargada, en una fuerza que insufla vida, energía para la mente, el alma y el espíritu. Una manera de proceder más que una teoría, que desemboca en la «escultura social», es decir, en toda manifestación que ayude al mundo a recuperar su alma, su espíritu y su solidaridad, y, una vez recobradas, poder instaurar la «plástica social» o la lucha para superar el capitalismo, e instaurar la tercera vía, el socialismo real.

En virtud de lo anterior, cabe considerar que la idea de estetizar la vida social, si bien entraña un marcado carácter emancipador pues su meta es que los ciudadanos alcancen su expresión, también implica un peligro: el de no reconocer sus derechos. Esta doble cara de la estetización de la política ya fue denunciada por Walter Benjamin en su estudio La obra de arte en la época de su reproductibilidad técnica, donde pone de manifiesto los usos y abusos de este concepto en su puesta en práctica por los regímenes fascistas. ${ }^{27}$

Volviendo al corpus teórico beuysiano, observamos cómo este no cesa de articularse mediante el diálogo intergeneracional para confluir finalmente en la puesta en escena de unas acciones innovadoras que, como la performance o el Body-art, exploran nuevos lenguajes mediante la fusión del artista con la obra. Es la década de los sesenta, momento en que muchas de las nuevas tendencias artísticas bebían de las fuentes de los mo-

\footnotetext{
${ }^{26}$ Comparte Beuys la visión nietzscheana del arte como desvelador, desocultador, deconstructor e intérprete del hombre, de la cultura y la sociedad modernas. Nietzsche argumenta al respecto: «Sólo a través de la sinceridad se tornará visible la angustia, la íntima miseria del hombre moderno. Sólo entonces será posible que el arte y la religión, a modo de un verdadero rescate, ocupen el lugar del pávido encubrimiento convencionalista y la mascarada, para implantar conjuntamente una cultura que responda a las genuinas necesidades del hombre en lugar de enseñarle, como es el caso de la cultura general contemporánea, a disimularlas y a convertirse así en una mentira ambulante» en Friedrich Wilhelm Nietzsche, Segunda consideración intempestiva: sobre la utilidad y los inconvenientes de la historia (Buenos Aires: Libros del Zorzal, 2006), 68-69.

${ }^{27}$ Walter Benjamin, La obra de arte en la época de su reproductibilidad técnica (México D. F: Itaca, 2003), 96-99.
} 
vimientos antiarte herederos de Marcel Duchamp —neo-dada en Nueva York, nouveau réalisme en París, Zero en Düsseldorf-. Al igual que entonces, se abogaba por una libre exploración de la realidad juntamente con el cuestionamiento del significado tradicional de los medios artísticos.

En el intento de reconciliar el arte con la vida, se impulsaron nuevas formas artísticas que no se centraban en la producción de artefactos, sino en la acción, la participación activa del público, la interactividad y la interdisciplinariedad. ${ }^{28} \mathrm{Y}$ en esta revolución debemos mencionar al colectivo Fluxus, cuyo principal ideólogo George Maciunas, junto a artistas como Wolf Vostell, Nam June Paik, Yoko Ono, Emmett Williams y el propio Joseph Beuys, apostaron decididamente por la acción. Será gracias a la performance — como vía expresiva y receptiva— que se auspiciaba el fin de las bellas artes y, al mismo tiempo, se dirigía la atención hacia fines socioconstructivos. ${ }^{29}$

A todo ello cabe añadir que en manos del artista alemán, la performance devendrá un acto iniciático que incorpora animales míticos, como la liebre, el alce, el coyote o la abeja. Actuaciones que supondrán un retorno al ritual donde los asistentes, ayudados por el collage de sensaciones y las palabras del «místico gurú», emprenderán un ejercicio de regresión ancestral como metáfora del camino hacia la curación psíquica tanto individual como colectiva. ${ }^{30}$

\footnotetext{
${ }^{28}$ Joseph Beuys, recogiendo las palabras vertidas por el Dr. Fausto de Goethe, comprenderá que el significado o sentido no reside únicamente en las palabras sino en la acción. La famosa sentencia bíblica "Al principio estaba el verbo» debe ser reemplazada por una proclama más apropiada a los tiempos modernos: "Al principio estaba la acción», porque el significado nunca se logra de una vez por todas, debe ser de nuevo conquistado en cada enunciado mediante las acciones verbales y las interacciones de hablantes, oyentes y lectores. Victoria Walters, Joseph Beuys and the Celtic Wor(l)d. A language of healing (Zurich: LIT Verlag, 2012), 28.

${ }^{29}$ Heiner Stachellhaus, Joseph Beuys (Barcelona: Parsifal Ediciones, 1990), 147.

${ }^{30}$ La performance, Manresa (Düsseldorf, 1966), destaca por adoptar la forma del ritual cristiano donde la cruz sirve como elemento para invocar a Ignacio de Loyola. El que fuera el fundador de la Compañía de Jesús y artífice de los Ejercicios espirituales es alabado por el artista alemán, puesto que su figura representa «la disciplinada conciencia interior, la capacidad de poner cada cosa en su lugar y de tomar la decisión de cambiar la vida y la dirección existencial del ser» Sabemos cuán importante fue el santo navarro para Beuys, y cómo la práctica de sus ejercicios le condujo a emprender un camino para superar sus varias crisis de sentido, llegando a alcanzar, según sus propias palabras, la libertad y autodeterminación del alma. AA. VV. Manresa-Hauptbahnhof: una experiència de Joseph Beuys a Catalunya inspirada en Ignasi de Loiola i Manresa (Barcelona: Fundació Caixa de Manresa, Generalitat de Catalunya, 1994), 46.
} 
Muchas son las críticas vertidas sobre Joseph Beuys, ya sean por su faceta de profesor de la Academia de Bellas Artes de Düsseldorf — que desarrollaremos más adelante- o debido a sus provocaciones estéticas. En efecto, su autoproclamada identidad artística como chamán o guía espiritual de la época, si bien puede parecer grandilocuente e incluso un tanto peligrosa - recordemos como todos los líderes de partidos totalitarios asumen la condición de líder absoluto y salvador de la comunidad- obedece, según el propio artista alemán, a una estrategia psicoanalítica que busca ahondar en las preguntas más que ofrecer respuestas cerradas y estructuradas en vías de poder de reactivar las energías vitales de la cultura.

It was thus a strategic stage to use the shaman's character but, subsequently, I gave scientific lectures. Also, at times, on one hand, I was a kind of modern scientific analyst, on the other hand, in the actions, I had a synthetic existence as shaman. This strategy aimed at creating in people an agitation for instigating questions rather than for conveying a complete and perfect structure. It was a kind of psychoanalysis with all the problems of energy and culture. ${ }^{31}$

Hay que añadir que sus performances, de marcado carácter pedagógico, cuestionan aspectos relacionados con el lenguaje, con la dificultad de explicar y entender las cosas desde otras maneras diferentes de "pensar»; un hecho que implica poner en acción aspectos minusvalorados por la lógica occidental, como son la intuición, la imaginación y el movimiento.

The problem lies in the word «understanding» and its many levels which cannot be restricted to rational analysis. Imagination, inspiration, and longing all lead people to sense that these other levels also play a part in understanding. This must be the root of reactions to this action, and is why my technique has been to try and seek out the energy points in the human power field, rather than demanding specific knowledge or reactions on part of the public. I try to bring to light the complexity of creative areas. ${ }^{32}$

\footnotetext{
${ }^{31}$ Norman Rosenthal y Heiner Bastian, Joseph Beuys: The Secret Block for a Secret Person in Ireland (London: Art Books Intl Ltd.,1999), 13.

${ }^{32}$ Robert Ayers, Marina Abramovic. En http:// www.artinfo.com/ news/ story/ 1537/ marina-abramovic/ (consultado el 20 abril de 2016).
} 
Así, la música, el sonido y las nuevas tecnologías, proporcionaban experiencias sensoriales que, como el tacto o el olfato, convertían el espacio de la performance en una Chóra. Nos referimos a esta tercera parte de naturaleza identificada como «espacio» o «receptáculo» situado entre el ser y el devenir, desarrollada por Platón en el Timeo y recogida por Gregory Ulmer para dar cuenta de la relación entre el arte y la pedagogía a través de las ideas de Jacques Derrida y Joseph Beuys. ${ }^{33}$ La Chóra representa el asiento, el lugar de recepción y desdoblamiento por el que cada historia, cada performance, es un receptáculo. Un recipiente - regido por una lógica híbrida, pues no es ni mito ni logos-que planteará deconstruir el significado de la propia producción artística considerando las relaciones que se establecen entre el locus y la génesis. Diríamos que el proyecto beuysiano no propone únicamente la regeneración social, sino que también ahonda en aspectos epistemológicos. Es decir, la reflexión teórica conduce a activar prácticas capaces de substituir el topos —en alusión a la lógica racional que impele a considerar las verdades como absolutas- por la Chóra, caracterizada por su no lugar, por su texto incierto y por el despliegue de analogías y metáforas vivas llenas de sentimiento. Por tanto, el acto pedagógico nunca se acabará en la transmisión de un "conocimiento cristalizado", sino por el desarrollo de energías vitales capaces de articular múltiples discursos cuya validez se proyectará como algo circunstancial y contextual.

Se constata cómo la educación se alza como eslabón para evolucionar y el arte como su modelo y principio fundamental. De hecho Beuys entendía — como ya lo hiciera Friedrich Schiller- ${ }^{34}$ que la resurrección del sentido comunitario solo sería posible recolocando el arte dentro del proceso educativo, pero, eso sí, nunca limitándose a una mera asignatura; todo el currículum debe estar impregnado de la visión artística para que los estudiantes experimenten — como dijo Rudolf Steiner- la creatividad como configuración de la libertad. ${ }^{35}$ Apoyándose en las tesis constructivistas que confían en las potencialidades de cada individuo para incidir en la configuración de su propia identidad, Beuys abogará por unas escuelas como entorno de formación en un sentido nuevo: del con-

${ }^{33}$ Gregory Ulmer, Applied Grammatology: Post(e)-Pedagogy from Jacques Derrida to Joseph Beuys (Baltimore, Johns Hopkins University Press, 1985), 148.

${ }^{34}$ Friedrich Schiller, Cartas a la educación estética del hombre (Buenos Aires: Aguilar, 1981).

${ }^{35}$ Rudolf Steiner, La filosofía de la libertad. Fundamentos de una concepción moderna del mundo (Madrid: Editorial Rudolf Steiner, 1999). 
cepto de Bildung se pasará al de Formung, entendida esta última como formación plástica. ${ }^{36}$ Un modelo pedagógico que se distancia así del ideal ilustrado debido a su pretensión universalista y a su vertiente excesivamente clásica y armonizadora.

\section{LA CREATIVIDAD COMO CIENCIA DE LA LIBERTAD: APUNTES DE EDUCACIÓN ESTÉTICO-POLÍTICA}

Lanzado por la nueva izquierda, se extendía por Alemania un sentimiento común, la autogestión escolar como alternativa a una pedagogía política generadora de políticas educativas ${ }^{37}$ que configuraban una educación autoritaria y represora de las auténticas necesidades del educando. Así fue como el malestar de la contracultura juvenil y estudiantil labró el camino que condujo al nacimiento, a finales de los años sesenta, de las Comunas Infantiles en ciudades como Stuttgart, Frankfurt y Berlín Occidental. Salvo algunas diferencias, estas asociaciones tenían como objetivos educativos el logro de la libertad individual, la capacidad crítica y de resistencia dentro de la situación contradictoria en la que vivían —en comunas, implantadas empero en un contexto social que se pretendía transformary, por último, la mediación de la libre satisfacción personal a través de la experiencia intensa de la libertad, el antiautoritarismo y la autogestión, así como de la liberación de los sentidos y la esfera intelectual. ${ }^{38}$

Experiencias que cuentan con un claro referente en el ámbito pedagógico alemán. Para ello, debemos retroceder más de sesenta años y reencontrarnos con una multitud de propuestas educativas de talante libertario en cuyo ideario destaca la educación artística como punto central y garantía de la verdadera concepción espiritual de la vida. Desde la Comunidad Escolar Libre de Wickersdorf, ${ }^{39}$ fundada en 1906 por el que fuera discípulo de

\footnotetext{
${ }^{36}$ Heiner Stachelhaus, Joseph Beuys (Barcelona: Parsifal Ediciones, 1990), 56.

${ }^{37}$ Para ahondar en las diferencias entre pedagogía política, política educativa y gestión político-educativa recomendamos la lectura de Ángel C. Moreu, (2000), «Pedagogia política i Política educativa», Temps d'Educació, 24 (2000): 141-167.

${ }^{38}$ Véase un completo estudio sobre las Comunas Infantiles en Chiara Sarraceno, Experiencia y teoría de las comunas infantiles: de la educación antiautoritaria a la educación socialista (Barcelona: Editorial Fontanella, 1977).

${ }^{39}$ Gustav Wyneken, Las Comunidades escolares libres (Madrid: Revista de Pedagogía, 1926). Junto a Wyneken, hay que destacar a Berthold Otto, responsable de la Hauslehrerschule instaurada cerca de Berlín en 1906, o a Paul Geheeb, creador de la Escuela de Odenwald inaugurada en 1910.
} 
Hegel, Gustav Wyneken (1875-1964), hasta las escuelas Waldorf ${ }^{40}$ (1919) - un acto de optimismo pedagógico después de la debacle de la Primera Guerra Mundial- cuyo impulsor, Rudolf Steiner, abogaba por una enseñanza en aras de propiciar una sensibilidad noble y espiritual.

Por consiguiente, y ya situados en los años sesenta, será preciso fundar escuelas y universidades libres, centros en los cuales la creatividad sea considerada una ciencia de la libertad. En definitiva, liberar al sistema escolar y universitario alemán de la empresa del Estado. Unos planteamientos que seguían la estela de las acciones protagonizadas por Michel Lobrot y Georges Lapassade que, en 1964, constituyeron el Grupo de Pedagogía Institucional (GPI) responsable de haber introducido en el ámbito escolar prácticas autogestionarias para fomentar un macrocambio político. ${ }^{41}$

En efecto, una juventud cada vez más politizada y convencida de la posibilidad de una alternativa real al sistema socioeducativo establecido invade Europa. En este contexto, Joseph Beuys, como docente de la Academia de Bellas Artes de Düsseldorf — plaza concedida por unanimidad en 1961-, inició un proceso de desobediencia que le comportaría la expulsión de la citada facultad. Como profesor de escultura, sus clases iban más allá de lo meramente artístico, pues le servían como plataforma política. Poniendo en práctica su lema "cada hombre es un artista», hizo caso omiso a los numerus clausus que imponían las políticas educativas, llegando a tener a su cargo 400 alumnos que, como ya predijo su maestro Mataré, quedaban fascinados tanto por su genialidad artística como por su discurso político.

Los coloquios públicos impartidos en su clase de la Academia se sucedían y, en 1967, entre lienzos, cinceles, bronce y barro, funda el Partido Alemán de los Estudiantes (Deutschen Studentenpartei als Metapartei). Considerado por Beuys un metapartido - al estimar que todo hombre es siempre un estudiante-, sus actas fundacionales reflejaban muchas de las inquietudes del maestro de escultura: supresión de los intereses nacionalistas, desarme absoluto, inexistencia de leyes de emergencia, la unidad de Europa y del mundo, elaboración de nuevos puntos de vista

\footnotetext{
${ }^{40}$ Patricia Quiroga y Olivia Girard, «La expansión de la pedagogía Waldorf: un análisis histórico», Temps d'Educació, 48 (2015): 91-109.

${ }^{41}$ Para profundizar sobre el tema, véase Antoni J. Colom, La pedagogía institucional (Madrid: Síntesis Educación, 2000), 144 y ss.
} 
para la enseñanza, la educación, la investigación, y también como fundamento para la economía, el derecho internacional y la cultura mundial.

Esta situación de marcado carácter combativo inquietó a los restantes miembros de la Facultad de Bellas Artes, que emprendieron una cruzada para deshabilitar al "artista-profesor-político» logrando finalmente su despido el 11 de octubre de 1972. Sin duda, la carta redactada en 1968 por diez profesores, entre ellos Götz, Weber, Bobek y Robaschik, muestra su desasosiego al considerar que Joseph Beuys usaba la propia facultad como un medio para difundir sus ideas en la sociedad. Acusado de ejercer una suerte de paternalismo ideológico y demagógico, se le atribuía, de igual modo, haber generado una situación crítica que afectaba tanto a los ámbitos artísticos como pedagógicos:

[Joseph Beuys] ha logrado ejercer una influencia peligrosa sobre el movimiento de reforma de nuestra facultad. Los representantes de los estudiantes, cuya cooperación y co-gestión han sido aceptados a modo de prueba por los catedráticos de común acuerdo con los representantes de los demás profesores, caen cada vez más en argumentaciones utópicas y anarquistas, y se están convirtiendo en los portavoces de esta ideología. Las reuniones degeneran en charlatanería pseudopolítica y críticas provocadoras que dan lugar a exigencias poco realistas, al mismo tiempo que se manifiesta una hostilidad abierta contra la democracia parlamentaria. ${ }^{42}$

En 1978 un fallo de la judicatura le dio la razón al considerar que su despido fue improcedente; aun así, el artista se negó a continuar la docencia en esta facultad. Pero las inquietudes sociopolíticas y vitales de nuestro protagonista le llevaron a fundar junto a Klaus Staeck, Georg Meistermann y Willi Bongard — basándose en los principios previamente redactados junto al Premio Nobel de literatura Heinrich Böll—, la Freie

\footnotetext{
${ }^{42}$ El contenido completo de la carta redactada por los profesores Götz, Weber, Bobek y Robaschik en Dusseldorf el 20-12-1968 se puede consultar en http://www.uclm.es/cdce/sin/sin5/profes.htm (consultado el 15 de septiembre de 2016). Por otro lado, una entrevista realizada por Peter Holffreter, Susanne Ebert, Manfred König y Eberhard Schweigert a Joseph Beuys ofrece la versión del artista. Peter Holffreter et al., Konununi1cation, 1 (Düsseldorf, 1973) http://www.ddooss.org/articulos/entrevistas/Joseph_Beuys.htm (consultado el 23 septiembre de 2016).
} 
Internationale Universität ${ }^{43}$ (Universidad Libre Internacional) el año 1977. Según se desprende del manifiesto fundacional, se trata de un modelo de educación superior que a lo único que está dispuesta es al control ciudadano. En ella no hay certificados, exámenes oficiales, numerus clausus, ni tampoco limitación por la edad. Solo enseñan profesores libres no oficiales, que, bajo su propia responsabilidad, firman los certificados de capacidad que entregan a sus estudiantes. Partiendo del concepto «todo hombre es un artista", la creatividad no se limita a aquellos que ejercen una de las artes tradicionales; es más, incluso en estos no se limita al ejercicio de su arte. En definitiva, gracias al intercambio de energías y a la igualdad de derechos entre profesores y alumnos será posible desarrollar la Formung o el potencial creativo propio de cada individuo.

$\mathrm{Al}$ acercarnos al plan de enseñanza de esta institución, descubrimos que, junto a las asignaturas de creación artística, se pretende incorporar unas «disciplinas intermedias» como, por ejemplo, pedagogía, teoría del conocimiento, comportamiento social, solidaridad, crítica de la crítica, crítica de arte, teoría de la literalidad, teoría de los sentidos, representación, teatro. También se prevén institutos para la ecología y la ciencia de la evolución. Además, la universidad se estructura en dos niveles: el nivel de escuela y el nivel de una exposición permanente que sirve como foro de exhibición y discusión de las obras artísticas. A los ojos de Beuys, la Universidad Libre Internacional constituía aquella «escultura social» que, en cumplimiento de su concepto artístico, culminaba en «la plástica social». Sin duda, el hecho de que el proyecto de la FIU cesara justo dos años después de la muerte del artista sugiere, además de los problemas internos y económicos para sobrellevar un proyecto de tal envergadura, la total dependencia de esta singladura con la figura del artista alemán.

\section{A MODO DE CONCLUSIÓN}

Llegados a este punto, es nuestra voluntad retomar la idea de performance que subyace en el concepto de Formung esbozado por Beuys. El porqué del interés prestado a los conceptos arriba planteados reside, se-

\footnotetext{
${ }^{43}$ Las sedes de la FIU (Freie Internationale Universität) en Munich, Hamburgo, Amsterdam y Batesville (Estados Unidos), entre otras, dan cuenta de la enorme repercusión de la iniciativa de Beuys en todo el mundo. La historia de la fundación de las diversas universidades, junto a un amplio abanico de informaciones acerca del artista pueden consultarse en http://www.beuys.org/ (consultado el 23 mayo de 2016).
} 
gún nuestro punto de vista, en que el artista alemán ya percibió el significado de educarse en tiempos posmetafísicos. Una cuestión que, sin duda, debería interpelarnos, pues incide directamente en la percepción y vivencia de nuestra subjetividad. Al paso, la noción de Formung nos lleva a plantear el proceso educativo de manera holística y como una aventura personal que, a modo de performance, deriva en un proceso abierto de autoeducación. En una sociedad donde se desdibujan los ritos de paso y donde todo es pasajero, adoptar la postura de no sucumbir a una identidad establecida por los discursos hegemónicos requiere de algo más que la simple oposición. Necesita un proceso estético capaz de realizar una rasgadura en los hábitos de juicio a favor de una práctica más arriesgada que busca actuar con artisticidad en la coacción. Porque lo que cuenta, no solo es nuestra capacidad de reconocer las maneras que los efectos coercitivos del saber están en funcionamiento en la misma formación del sujeto, sino también de poner en riesgo el propio desarrollo de uno como sujeto.

La Formung nos habla de aquellas acciones que uno ejerce sobre sí, modificándose, purificándose, transformándose en un despliegue constante de actitudes éticas hacia uno mismo, los otros, y el mundo. Y en la confluencia entre el «yo»el «tú»y «el otro» se encuentra el recuerdo. Un acto, el de recordar, eminentemente creativo a la vez que performativo, pues despliega una red de significados y significantes que acaban produciendo aquello que se intenta describir. En otras palabras, el recuerdo esculpe nuestra subjetividad. Como ya anunciara Jerome Bruner, en el momento en que una cultura proclama una historia o una memoria oficial y ésta pasa a ser de dominio público, el mismo hecho se convierte en responsable de alterar el proceso de configuración de nuestro yo y de nuestra relación con la alteridad. ${ }^{44}$

De ahí surge la necesidad de una educación que también tenga como punto de referencia una estética de la memoria capaz de trascender hacia acciones transformadoras a fin de hacer frente a la intolerancia. Una posición que establece el compromiso de no olvidar el sufrimiento del otro, del distinto, del que no recuerda como nosotros. A vueltas, esta postura nos impele hacia la responsabilidad, pues no somos otra cosa que un homo dramaticus, individuos que, en continua performance, transitamos

\footnotetext{
${ }^{44}$ Jerome Bruner, Actos de significado. Más allá de la revolución cognitiva (Madrid: Alianza Editorial,
} 1991), 110. 
por el laberinto de un mundo que no nos ofrece protección. Alejados del ideal neoclásico de la Bildung — cuya finalidad consistía en la construcción armónica del individuo mediante la adquisición de una alma bella (Kalós) en un cuerpo bien proporcionado (Agathós) - lo que impera en estos tiempos poshumanos es el concepto de Formung, entendido como un continuo proceso plástico de construcción y deconstrucción de uno mismo sin negar la posibilidad de fugas y divergencias. Al fin y al cabo, y como artistas que somos, estamos obligados a interpretar y a interpretarnos continuamente activando procesos de reflexión crítica para determinar la voluntad de adaptarse, resignarse o confrontarse con los intrincados elementos que conforman esta gran y siempre imperfecta carpa circense que engloba nuestra realidad social.

\section{Nota sobre la autora:}

RaQuel Cercós i Raichs es licenciada en Pedagogía y profesora asociada del Departamento de Teoría e Historia de la Educación en la Universidad de Barcelona. Miembro del grupo de investigación en Educación Moral (GREM). Actualmente investiga los conceptos, discursos y narrativas pedagógicas de la masculinidad a través de los vínculos que se establecieron en la época victoriana entre la cultura, la educación y el género. Por otro lado ha realizado incursiones en las teorías feministas, así como en los discursos éticos y estéticos posmodernos. Ha participado en diversos coloquios nacionales e internacionales de Historia de la Educación y publicado en revistas especializadas. 